\section{Climate Dynamics}

August 2005, Volume 25, Numbers 2-3: Pages 219-

236

http://dx.doi.org/10.1007/s00382-005-0030-7

(c) 2005 Springer Verlag
Archimer, archive institutionnelle de l'Ifremer http://www.ifremer.fr/docelec/

The original publication is available at http://www.springerlink.com

\title{
A high-resolution 44-year atmospheric hindcast for the Mediterranean Basin: contribution to the regional improvement of global reanalysis
}

\author{
M. G. Sotillo ${ }^{1, *}$, A. W. Ratsimandresy ${ }^{1}$, J. C. Carretero ${ }^{1}$, A. Bentamy ${ }^{2}$, F. Valero ${ }^{3}$ and F. González- \\ Rouco $^{3}$
}

\footnotetext{
${ }^{1}$ Área de Medio Físico, Ente Público Puertos del Estado (EPPE), Av. Partenón, 10, 28042 Madrid, Spain

${ }^{2}$ Institut Français de Recherche pour l'Explotation de la MER (IFREMER), BP 70, 29280 Plouzané, France

${ }^{3}$ Dpto. Astrofísica y Física de la Atmósfera, Facultad de Ciencias Físicas, Universidad Complutense de Madrid, 28040 Madrid, Spain
}

*: Corresponding author : Sotillo M.G., email address : marcos@puertos.es

\begin{abstract}
:
A 44-year (1958-2001) high-resolution atmospheric hindcast for the whole Mediterranean Basin was performed within the EU-funded Hindcast of Dynamic Processes of the Ocean and Coastal Areas of Europe (HIPOCAS) Project. The long-term hindcasted data set, which comprises several atmospheric parameters at different levels, was produced by means of dynamical downscaling from the NCEP/NCAR global reanalysis using the atmospheric limited area model REMO. The REMO hindcast has been exhaustively validated. On that score, various hindcasted surface parameters, such as 10-m wind field, 2-m temperature and mean sea level pressure, have been compared to satellite data (ERS$1 / 2$ scatterometer) and in-situ measurements from offshore stations. In addition, two ocean models (waves and sea level) have been forced with REMO hindcasted fields (mean sea level pressure and 10-m wind field). The validation of these ocean runs, performed through comparisons of simulated waves and sea level with oceanographic measurements, allows to evaluate "indirectly" the quality of the REMO hindcasted data used as atmospheric forcing. Once the quality of the hindcasted data was verified, the efficiency of the regional enhancement performed through dynamical downscaling on the NCEP global reanalysis was assessed. The regional improvement was evaluated through comparisons of REMO and NCEP performance in reproducing observations. The important improvement obtained in the characterization of extreme wind events is particularly remarkable.
\end{abstract}


In recent years, there has been a growing concern on the need of long-term information about prevailing environmental conditions in order to assess the climate and plan sustainable development of economic and scientific activities in European waters. In addition to this growing necessity, the present lack of long-term homogeneous oceanographic and atmospheric databases have motivated research efforts leading to the generation of long-term environmental databases useful to assess climate variability (Juang et al. 1997; Günter et al. 1998; Ebisuzaki et al. 1998; Cox and Swail 2001; Feser et al. 2001; Guedes et al. 2002; Mesinger et al. 2003).

The major methodological drawback for a multi-decadal assessment of Mediterranean climate and its variability comes from the lack of suitable observation and/or simulated data. The existing long-term databases, both in terms of local observations and analysed products, present some sort of inhomogeneities. Observation networks show irregular spatial distributions as well as temporal inhomogeneities linked to changes and improvements in the measurement methodologies and devices. On the other hand, databases based on analysis, which are an adequate tool to study meteorological cases or short-time periods, are almost useless for climate studies focused on multi-decadal periods (Günter et al. 1998). The existence of temporal inhomogeneities is the consequence of the continuous improvement introduced in the analysis systems (i.e. improvement in the resolution of the models, increase of the amount and quality of assimilated data, impact of new measurements such as those obtained from satellite). In order to avoid this commonly named "sudden" inhomogeneity problem (Karl et al. 1993; Jones 1995) and to create useful climate databases, a number of institutions (such as NCEP/NCAR, ECMWF, NASA, and others) have made efforts to produce the so-called global reanalysis. For that, they have assimilated weather observations of the past decades with the same frozen state-of-the-art analysis scheme (Kalnay et al. 1996; Gibson et al. 1997; Uppala 2001; Rood et al. 2001).

The inhomogeneity problem is not expected in the global reanalysis data. Nevertheless, the use of these global reanalysis in regional climate studies presents some limitations due to their coarse spatial resolution. Typical reanalysis resolution allows to solve large scale feature but fails to reproduce the regional and local scale details related to the interaction of large scale circulation with regional geographical features such as orography, land-sea distribution and soil types (Von Storch 1999). Therefore, when interested on areas marked by complex orography (e.g. Mediterranean Basin) and especially on surface parameters (such as 10-m wind field or 2-m temperature), the coarse resolution used in global reanalysis data is certainly a shortcoming. This motivates the need of producing long-term and high-resolution homogeneous databases.

Within this context, the HIPOCAS Project (Hindcast of Dynamic Processes of the Ocean and Coastal Areas of Europe), funded by the EU's Environment Program, was established to produce long-term high-resolution homogeneous wind, wave, and sea level databases to assess the climate, as well as its trends and variability over European Waters (Guedes et al. 2002).

The present paper is focused on the atmospheric hindcast performed by Ente Público Puertos del Estado (EPPE) over the Mediterranean Basin, covering a long-term period of 44-year (19582001). Special attention is given to the validation of the results as well as to the evaluation of the improvement introduced by the hindcast on already existing climate reanalysis data.

The atmospheric hindcast database was generated using the regional model REMO (Jacob and Podzum 1997) following a dynamical downscaling technique. With this technique, the large-scale information, reliably simulated by global climate models, is transferred to smaller scales. For that, GCM data are used to drive atmospheric limited area models, whose outputs represent a regional enhancement of the GCM forcing fields (Giorgi 1990; Podzum et al. 1995; Kidson and Thomson 1998; Rinke and Dethloff 2000).

This regional enhancement of global reanalysis produces a data set we expect to be, especially useful to those environmental scientists working with regional and local models (e.g. ocean, hydrology, landsurface, particletransport) and who are in need of atmospheric high-resolution surface parameters (i.e. wind, temperature, humidity) to drive their models.

The organization of the paper is as follows. A brief description of the numerical model and the set up used to perform the hindcast is given in Sect. 2. Section 3 is devoted to verify the quality of the hindcasted data through extensive comparisons with observations from different sources. Section 4 presents the differences in the performance of the hindcast and the global reanalysis in reproducing the observations. Finally, the main conclusions are drawn in Sect. 5. 


\section{Model set up and Mediterranean hindcasted data}

\subsection{Model description}

The regional atmospheric climate model REMO (Jacob and Podzun 1997) was used to perform the 44-year hindcast for the whole Mediterranean Basin. This numerical model is the result of a co-operative project of the Deutsches KlimaRechenZentrum (DKRZ), Deutscher Wetterdienst (DWD), GKSS-ForschungsZentrum (GKSS) and Max Planck Institute für Meteorologie (MPI).

The hydrostatic REMO model was set up in its climatic mode. This specific configuration implies the use of the same parameterization scheme as in the GCM ECHAM4 (Roeckner et al. 1996). Despite of using a climatic physic scheme, the dynamical scheme of REMO is similar to the one used by the DWD EM/DM regional forecast operative system (Majewski 1991). It is based on the primitive equations in a terrain-following hybrid co-ordinate system. The numerical model is horizontally formulated for an Arakawa-C grid through second order central differences. The vertical finite difference formulation follows that of Simmons and Burridge (1981).

Prognostic variables are surface air pressure, horizontal wind components, temperature, specific humidity and cloud water content. Physical processes such as radiation (short and long wave), vertical diffusion, stratiform condensations, convective and surface processes, all of them contributing on the sub-grid scale, were considered as in the GCM ECHAM4. Parameterization of short and long-wave radiative energy transfer was accomplished by following Morcrette et al. (1986), with modifications for additional greenhouse gases, $14.6 \mu \mathrm{m}$ ozone band, and various types of aerosols. Vertical diffusion and turbulent surface fluxes are resolved from Monin-Obukov theory following Louis (1979). Stratification cloud water content is calculated after Sundquist (1978), whereas cumulus convection is parameterized by a mass flux scheme (Tiedtke 1989) with modifications after Nordeng (1994). It is also worthy to note that a five-layer soil model is included in order to take into account heat and water budgets within the soils (DKRZ 1994).

\subsection{Experiment description}

The 44-year (1958-2001) Mediterranean hindcast was performed with a horizontal resolution of $0.5 \times 0.5^{\circ}$ (roughly $50 \times 50 \mathrm{~km}^{2}$ ). The model domain is covered by $101 \times 61$ grid points, and it is wide enough to incorporate the whole Mediterranean Basin within the hindcast area, and also includes a eight-point "sponge zone" from the boundaries to relax prognostic variables towards prescribed boundary fields (Davies 1976). The model was run on a rotated spherical grid with its North Pole sited at $51.0^{\circ} \mathrm{N}, 167.0^{\circ} \mathrm{W}$. This grid rotation was applied in order to fix the model equator line along the middle of the selected geographical domain; thus a minimum distortion due to latitude in the grid-cell size is achieved. Twenty hybrid levels $(\eta)$ were considered in the vertical. A time step of $300 \mathrm{~s}$ was adopted.

REMO is forced over the whole run period with NCEP/NCAR global reanalysis (Kalnay et al. 1996). Figure 1a displays the spatial domain covered by the REMO simulation. The spatial resolution is enhanced by a factor of four both in longitude and latitude in comparison to NCEP global reanalysis (T62 grid, equivalent to a horizontal resolution of about $210 \mathrm{~km}$, Fig. 1 b). In consequence, a noticeable improvement on characterization of regional orographic features and land-sea distribution was introduced (compare both panels of Fig. 1). 

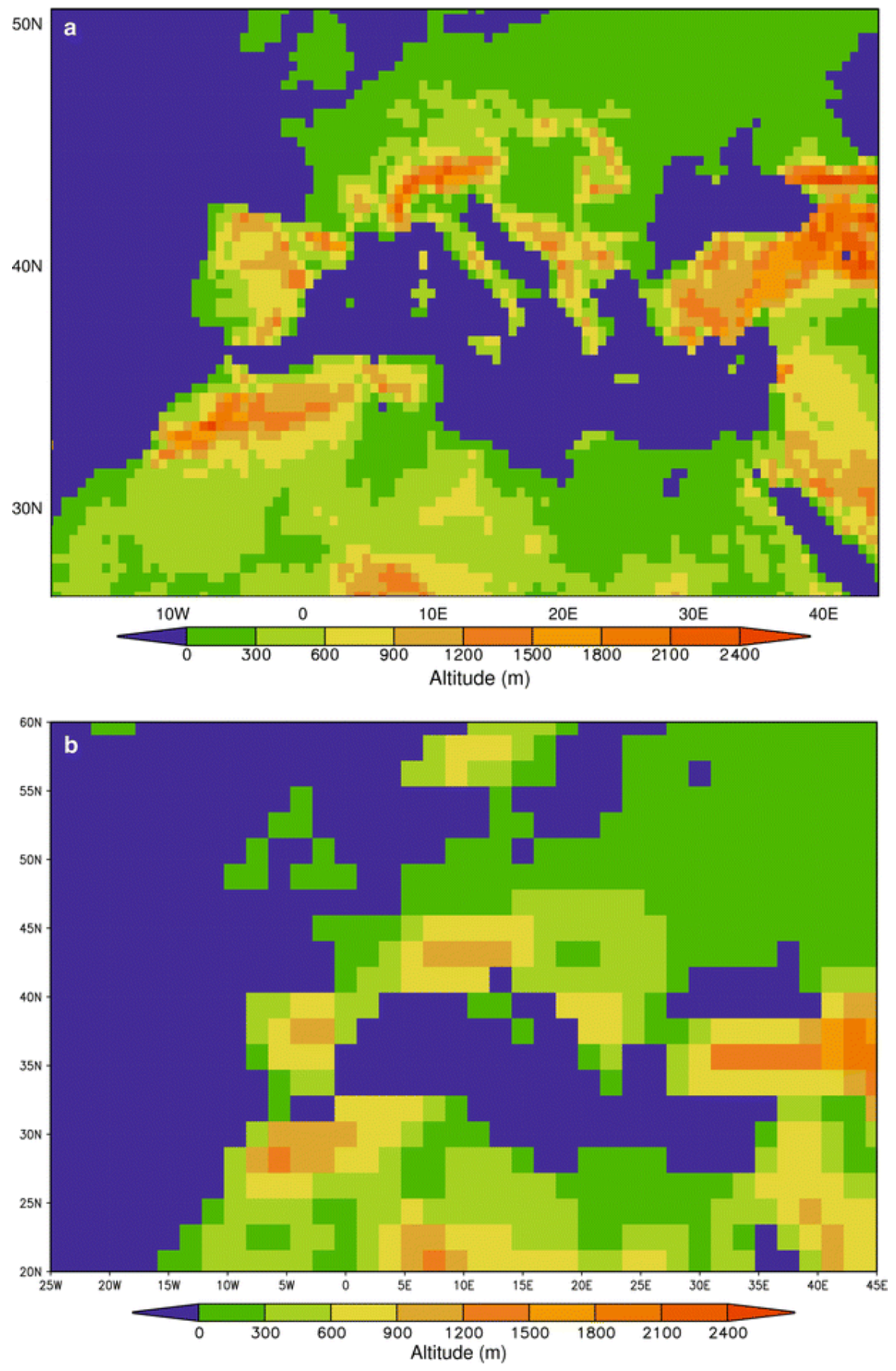

Fig. 1 (a) REMO Mediterranean domain and orography (in $\mathrm{m}$ ) according to its resolution. (b) Orography and land-sea mask used in the NCEP global reanalysis.

A spectral nudging technique (Von Storch et al. 2000) has been used in the REMO run to impose time-variable large-scale atmospheric states. The applied technique is based on keeping model solution close to NCEP reanalysis values at those scales (the largest ones) for which we have the highest confidence in the quality of the reanalysis used as forcing. At the same time, the model is free to resolve the smaller scales and regional features independently of the forcing data. All this is achieved by adding nudging terms in the spectral domain with maximum efficiency for smaller wave numbers and higher altitudes. This spectral nudging technique has been applied only to the zonal and meridional wind components.

It is important to point out that during the set up of the hindcast, a rigorous attention was devoted to the production of surface parameter fields used to drive wave and sea level models. To do this, different tests to study the sensitivity of simulated $10-\mathrm{m}$ wind field were performed by changing 
the roughness length over sea and land, as well as changing the forcing which drives the REMO model: ERA15 instead of NCEP global reanalysis (Sotillo 2003).

The SST data set used as boundary condition along the 44-year REMO run comes from the one used in the NCEP reanalysis. The analysis and climatologies used in the generation of such NCEP SST boundary field were the following ones: starting from 1982, when Advanced Very High Resolution Radiometer (AVHRR) data became available, an optimal interpolation of Reynolds SST reanalysis (Reynolds and Smith 1994) was used. For earlier periods, the UKMO global ice and SST (GISST) reanalysis was used (Parker et al. 1993). The accuracy of these SST analysis has been investigated through comparisons with buoy data moored at different oceanic basin (Bentamy et al. 2003).

The total REMO output, made of over 280 fields, was stored hourly over the whole run period. This output comprises various parameters such as temperature, geopotential height, specific humidity and wind components at the 20 levels resolved by the model, in addition to other single level parameters such as fractional cloud cover, net surface solar and thermal radiation, total accumulated precipitation, surface sensible and latent heat fluxes, and many more. The present paper is focused on surface parameters, namely 2-m temperature, mean sea level pressure, and especially $10-\mathrm{m}$ wind field.

\section{Quality of HIPOCAS Mediterranean data: REMO validation}

An exhaustive validation of the hindcasted data has been carried out. The aim of this verification is to highlight the confidence on the REMO hindcasted data and to check its limitations. The validation of the REMO run has been performed through comparisons of different hindcasted variables with observations. These observations are from different sources: offshore meteorological in-situ measurements from buoys, in-situ measurements from inland stations, satellite data, as well as analysis (ECMWF) and reanalysis data (NCEP/NCAR and ERA15). In addition, an "indirect" REMO validation has been performed through oceanic models. In this respect, some REMO hindcasted fields (mean sea level pressure and 10-m wind field) have been used as driving fields for different oceanic models (waves and sea level). Comparisons of their outputs with oceanographic in-situ measurements allow us to evaluate the quality of the hindcasted atmospheric fields used as forcing. Such a use of oceanographic measurements as an atmospheric proxy data allows us to validate the REMO model over offshore areas where the lack of meteorological measurements is certainly a shortcoming.

\section{1. "Direct" REMO validation}

Examples of the comparisons of REMO hindcasted parameters and in-situ measurements, in addition to satellite data, are shown in this section. This validation was focused mainly on the surface parameters such as mean sea level pressure, 2-m temperature and especially on 10-m wind field.

The reason for focussing the model validation on surface fields is because dynamical downscaling introduces more detail with respect to the global reanalysis used as driving fields at the surface layer. Furthermore, these surface parameters are also used as forcing fields for longterm oceanographic hindcasts. The added value introduced by the downscaling on the surface parameters is linked to the better characterization of the interplay between large-scale atmospheric conditions and regional features (i.e. mountain ranges, marginal seas). The quantification of this added value introduced by the dynamical downscaling will be shown with more detail in Sect. 4.

\subsubsection{REMO versus offshore observations}

The REMO hindcast has been validated with in-situ measurements obtained from 15 Atlantic and Mediterranean offshore buoy stations (Table 1 and Fig. 2 illustrate their locations). The observations and the REMO simulation provide hourly frequency data; however, they were re- 
sampled with the same temporal resolution as the NCEP reanalysis, i.e. 00, 06, 12 and 18 UTC, for further comparison purposes (see Sect. 4).

Table 1 Statistical comparisons of REMO 10-m wind speed $\left(\mathrm{m} \mathrm{s}^{-1}\right)$ with in-situ observations and analogous comparisons between NCEP reanalysis wind speed and the same observations

\begin{tabular}{|c|c|c|c|c|c|c|c|c|}
\hline \multirow{2}{*}{ CODE (location) } & \multirow{2}{*}{$\mathrm{N}$} & \multirow{2}{*}{$X_{\text {obs }}$} & \multicolumn{3}{|c|}{ REMO } & \multicolumn{3}{|c|}{ NCEP } \\
\hline & & & $r$ & RMSE & Bias & $r$ & RMSE & Bias \\
\hline $2.4 \mathrm{~W})$ & 6651 & 8.88 & .88 & 1.99 & -0.12 & .78 & 2.62 & -0.32 \\
\hline BV & 107 & 7.95 & 84 & 07 & .06 & .79 & 2.32 & 0.19 \\
\hline ZVIZ & 86 & 7.65 & .83 & 2.17 & 0.14 & .75 & 2.53 & -0.21 \\
\hline EÑ & 946 & .38 & .66 & 93 & 0.85 & .47 & 3.19 & 0.07 \\
\hline ESTA & 3948 & 3.23 & .76 & 58 & -0.14 & .66 & .04 & 0.0 \\
\hline SILLI & 105 & 7.52 & .75 & 51 & -0.80 & .63 & 91 & 10.0 \\
\hline CAD & 149 & .45 & .68 & 2.40 & -0.03 & .41 & 82 & -2.5 \\
\hline ALBC & 4201 & 0.62 & .46 & 10 & -0.27 & .41 & 4.02 & -2.7 \\
\hline $\mathrm{CGA}^{-}$ & 3485 & 7.03 & .66 & 3.03 & -1.14 & .57 & 4.05 & -2.68 \\
\hline BMAH & 3682 & 7.03 & .66 & 2.87 & -0.48 & .61 & 3.05 & -0.84 \\
\hline 13.4N, 7.8E) & 2357 & 7.74 & .65 & 4.23 & -1.91 & .49 & 4.76 & -2.00 \\
\hline ZADRI (45.0N, 13.0E) & 4460 & 6.73 & .62 & 3.25 & -1.00 & .48 & 3.97 & -1.88 \\
\hline ZATHO (40.0N, 24.7E) & 1608 & 6.57 & .71 & 2.93 & 0.24 & .62 & 3.57 & -1.76 \\
\hline ZMYKO ( & 1711 & 9.33 & .65 & 3.44 & -1.37 & .59 & 4.42 & -2.94 \\
\hline ZSA & 2589 & 7.38 & 65 & 36 & 0.09 & .63 & 3.00 & -1.05 \\
\hline Mea & 59985 & 7.43 & 70 & 32 & -0.39 & .59 & 42 & -1.36 \\
\hline Mea & | & 7.58 & 77 & & 0.00 & 64 & 1 & -0.66 \\
\hline ear & 24093 & 7.30 & .63 & 1 & 0.73 & .55 & 36 & -1.9 \\
\hline
\end{tabular}

Parameters: name and location of each station, number of measurements $(\mathrm{N})$, mean observed value in $\mathrm{m} \mathrm{s}^{-1}\left(\mathrm{X}_{\mathrm{obs}}\right)$, correlation index ( $\mathrm{r}$ ), root mean square error (RMSE) in $\mathrm{m} \mathrm{s}^{-1}$, and bias (in $\mathrm{m} \mathrm{s}^{-1}$ ). Mean parameters considering overall, Atlantic and Mediterranean station averages are also provided. In-situ observations measured at the 15 offshore stations. REMO and NCEP data obtained from the closest REMO grid point to each station.

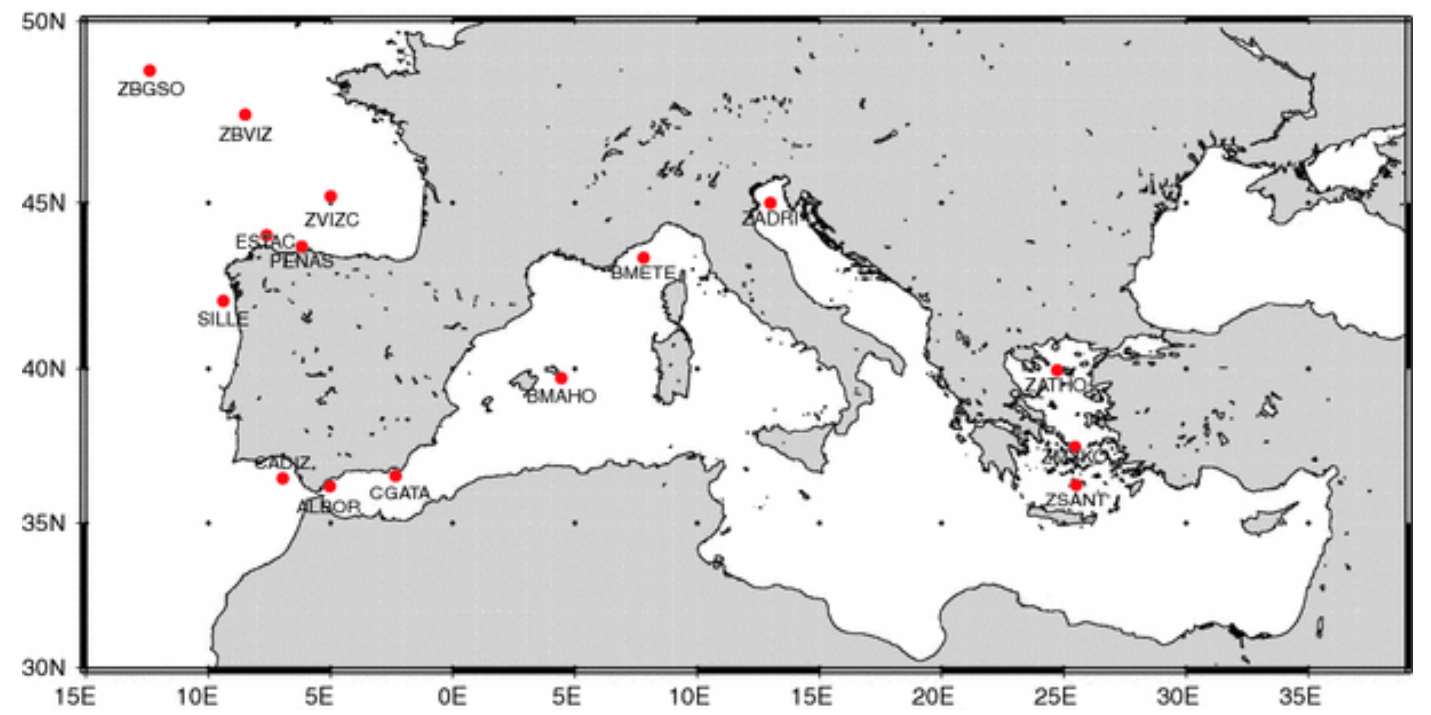


Fig. 2 Geographic positions of the 15 offshore meteorological stations used in the REMO validation as well as in the comparisons with the NCEP global reanalysis

The direct comparison between simulated and observed data was performed selecting the REMO grid point closest to the station position. A comment is worth on the intrinsic differences between observed in-situ measurements and grid point simulated data. Whereas the former is a local measurement resulting from the contribution of the whole range of scales, the latter is the result of a horizontal spatial average over the grid cell (approx. $50 \mathrm{~km} \times 50 \mathrm{~km}$ ). Differences between both types of data could be significant, specially over land and coastal areas where ruling local aspects such as orography, land-sea proportion, and related thermal and dynamical effects can be smoothed out by the spatial averaging (Frank 2001).

The comparison presented in this section is focussed on offshore areas where the relative homogeneity of sea surface ensures a minimal effect of the above uncertainties. Thus, differences between offshore observations and REMO simulations should be mostly due to model misbehaviour or problems in the in-situ data acquisition process rather than to indirect effects of orography and the averaging.

It is also worth to note that with the exception of the three Atlantic buoys (ZBGSO, ZBVIZ and $Z V I Z C)$ the offshore measurements used to validate the hindcast were not previously assimilated by the NCEP global reanalysis. Therefore, a complete independence between simulated data and observations used for the validation is guaranteed. This full independence between the predictor and the predictant allows evaluating adequately the model's skill.

Comparisons between observed and REMO simulated mean sea level pressure performed at each of the 15 offshore stations showed that REMO reproduces quite well the temporal evolution of such variable both in the Atlantic and Mediterranean Basins. Statistical analysis render linear correlations higher than 0.95 with negligible biases (observation minus model, lower than $0.5 \mathrm{hPa}$ ). As an example, Fig. 3 illustrates such high quality of REMO mean sea level pressure data for a 1-year period at the Mediterranean buoy CGATA.

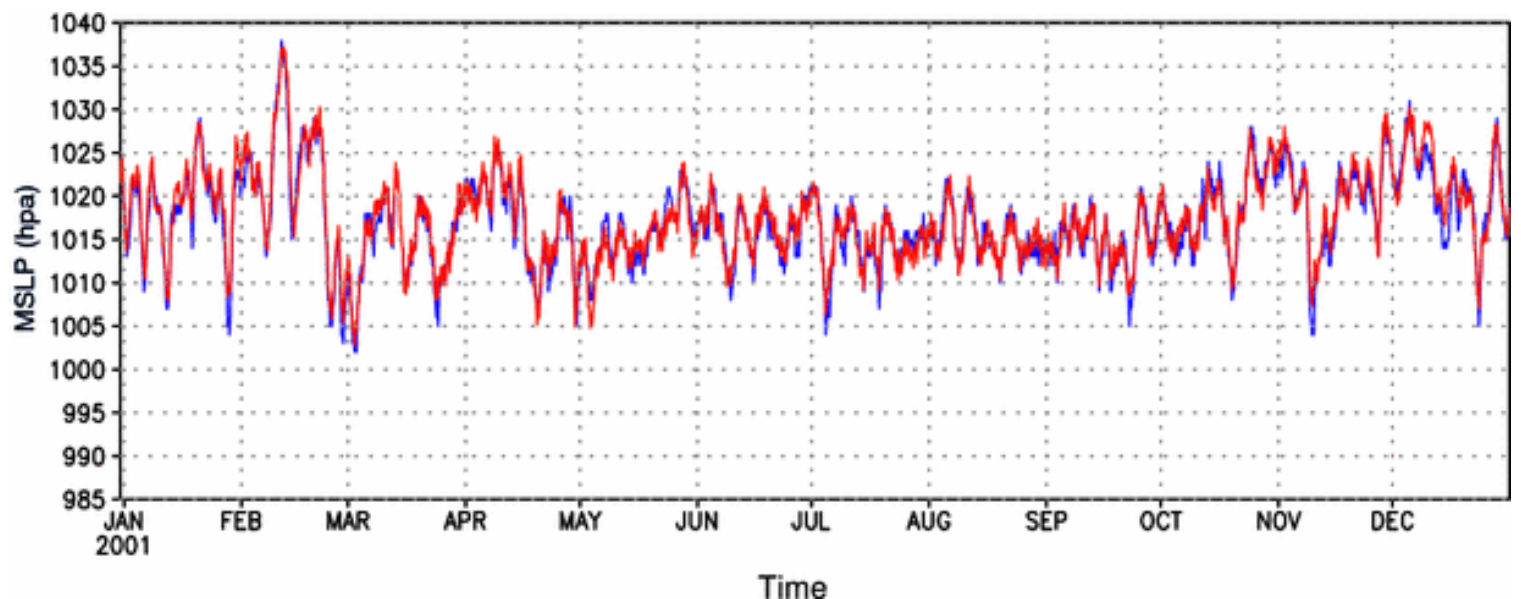

Fig. 3 Temporal evolution of observed (blue line) and REMO simulated (red line) mean sea level pressure (in $\mathrm{hPa}$ ) at CGATA offshore station (36.57 N, $2.33 \mathrm{~W}$ )

The good agreement was also observed with the comparisons of 2-m temperature. For 14 stations, where temperature data were available, only three have shown correlation values lower than 0.94 , being the minimum correlation value (0.90) obtained with the ALBOR buoy moored close to the Strait of Gibraltar. A small positive bias (less than $1 \mathrm{~K}$ ) is obtained with almost every station.

With respect to the 10-m wind field, comparisons were performed at the 15 offshore stations and the statistic parameters are shown in Table 1. Correlations between 0.66 (PEÑAS) and 0.87 (ZBGSO) are obtained with the Atlantic stations. Slightly lower values are obtained over the Mediterranean Basin (values between 0.62 and 0.71 for ZADRI and ZATOS, respectively), although an anomalous low correlation value $(0.46)$ is observed in the Strait of Gibraltar (ALBOR). This low correlation value seems to be linked to the fact that the complex orography of 
this area along with other local factors (i.e. the strong breeze regime) determinant in the surface wind field are not completely well resolved by regional models like REMO.

These differences between Atlantic and Mediterranean Basins are also observed with RMSE values of $2.0-2.9 \mathrm{~m} \mathrm{~s}^{-1}$ for the Atlantic stations and $2.9-4.2 \mathrm{~m} \mathrm{~s}^{-1}$ for the Mediterranean ones. With respect to the bias, one should note that 10 out of 15 stations present negative bias. However, only 3 out of these 10 stations show an underestimation of the observed wind speed higher than $1 \mathrm{~m} \mathrm{~s}^{-1}$. Figure 4 illustrates how REMO reproduces the wind speed and wind direction at the ESTAC station.
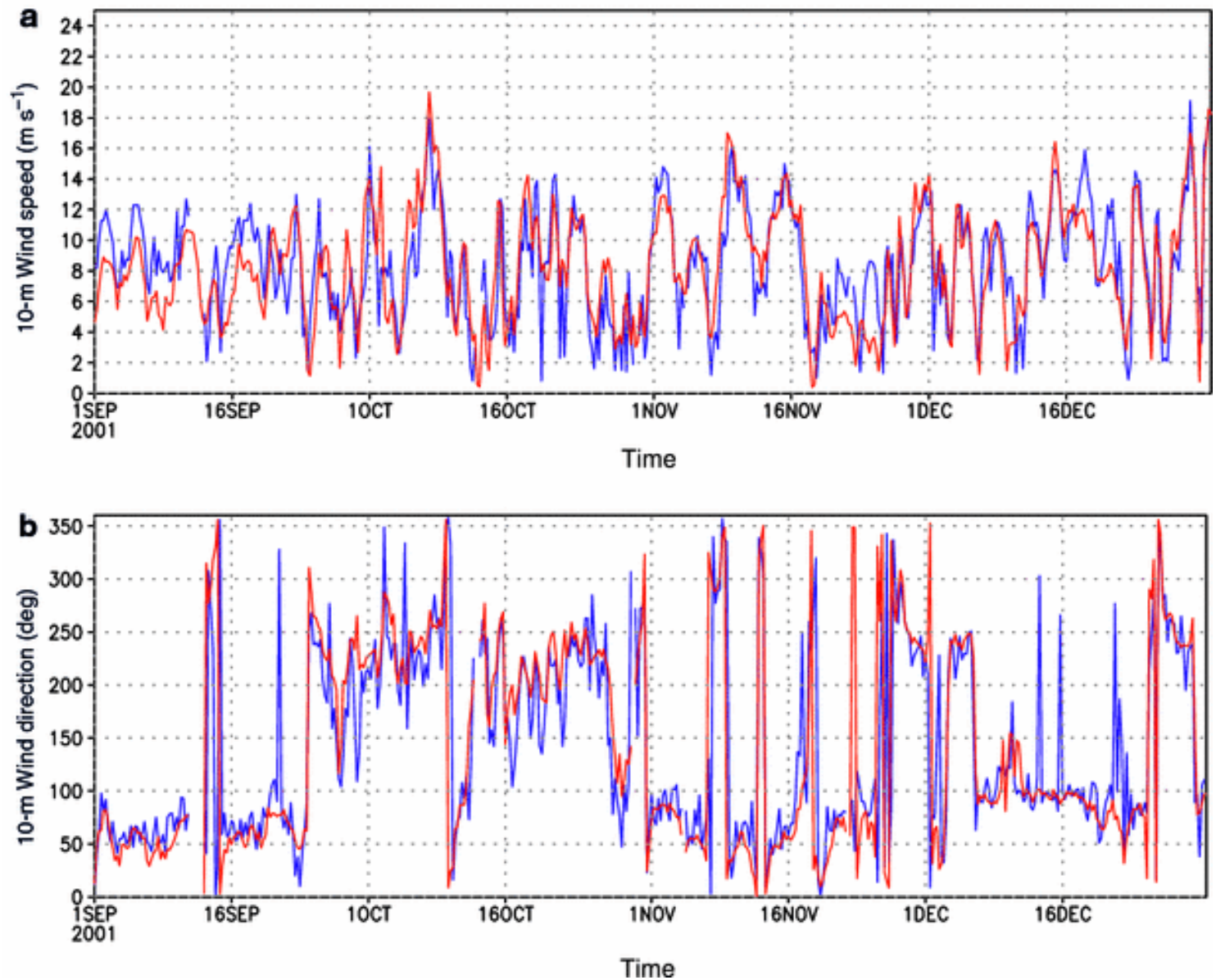

Fig. 4 Temporal evolution of observed (blue line) and REMO simulated (red line) (a) 10-m wind speed (in $\mathrm{m} \mathrm{s}^{-1}$ ) and (b) 10-m wind direction (in deg from North) at ESTAC offshore station $(44.06 \mathrm{~N}, 7.62 \mathrm{~W})$

Offshore comparisons of REMO hindcasted data and in-situ measurements suggest that the simulation reproduces with great reliability, the observed mean sea level pressure and the 2-m temperature fields. This is also valid for the $10-\mathrm{m}$ wind field with REMO reproducing it better in the Atlantic than in the Mediterranean.

\subsubsection{REMO versus satellite data}

REMO surface winds were also compared with the $10-\mathrm{m}$ wind field derived from scatterometer data over the Mediterranean Basin for the 1991-2001 period. These remote sensed wind data were obtained from the scatterometer onboard of the European missions ERS-1/2. 
The accuracy of this scatterometer retrieved wind data has been thoroughly investigated through comprehensive comparisons with buoy wind measurements over several oceanic basins (Graber et al. 1996; Bentamy et al. 1998; Quilfen et al. 1999; Bentamy et al. 2002), which have shown that both ERS-1/2 wind speed and direction present a high agreement with in-situ offshore observations from buoy stations. This makes the ERS wind data an useful tool to validate REMO 10-m winds over the whole Mediterranean Basin.

In order to allow comparisons between remotely sensed winds and the regional REMO hindcasted wind field, the later is interpolated in space and in time to the scatterometer cell positions. This REMO-ERS "collocation" is carried out for all scatterometer observations occurring within half an hour from REMO simulated data. Spatial and temporal interpolation of REMO data is based on a standard linear weighting procedure from the four closest surrounding model grid points. For the whole study period, more than 2.7 millions of validated wind data were collocated $\left(65 \%\right.$ of which are located between $32^{\circ} \mathrm{N}$ and $38^{\circ} \mathrm{N}$, whereas only $7 \%$ north of $42^{\circ} \mathrm{N}$ ).

For these comparisons, the residuals, defined as the difference between REMO and ERS data, were computed for 10-m wind speed and direction. The residuals were calculated separately as a function of wind speed, wind direction as well as latitude and longitude. Figure 5 shows the behaviour of the residuals of 10-m wind speed and wind direction depending on ERS wind speed (an interval of $1 \mathrm{~m} \mathrm{~s}^{-1}$ is used). This plot suggests that REMO overestimates the satellite winds lower than $4 \mathrm{~m} \mathrm{~s}^{-1}$ and underestimates extreme winds (those higher than $11 \mathrm{~m} \mathrm{~s}-1$ ). However, note that within the thresholds of 3-11 m s-1, where most of the values are found, the residuals are lower than $1 \mathrm{~m} \mathrm{~s}^{-1}$. On the other hand, the mean and the standard deviation of wind direction residuals are quite constant for all wind speed values. The main discrepancy between REMO and satellite wind estimates is found at low wind conditions. No important dependency of wind speed residuals on wind direction, longitude nor latitude was detected (not shown). Table 2 depicts the main statistical parameters that characterize the differences between REMO and scatterometer wind field. Calculations were performed over the whole Mediterranean and over sub-basins, which divide the Mediterranean into three regions: the westernmost Mediterranean (MEDI; $6^{\circ} \mathrm{W}-5^{\circ} \mathrm{E}, 35^{\circ} \mathrm{N}-44^{\circ} \mathrm{N}$ ), the area centred in the Tirrenum Sea and the Genoa Gulf (MEDII; $6^{\circ} \mathrm{E}-15^{\circ} \mathrm{W}, 36^{\circ} \mathrm{N}-44^{\circ} \mathrm{N}$ ), and the easternmost Mediterranean (MEDIII; $15^{\circ} \mathrm{E}-30^{\circ} \mathrm{E}, 30^{\circ} \mathrm{N}-38^{\circ} \mathrm{N}$ ). The overall correlation value between REMO and ERS data is 0.70 . The standard deviation of the wind speed residuals is $2.4 \mathrm{~m} \mathrm{~s}^{-1}$. None noticeable bias is observed neither in speed nor in direction. When comparing the three sub-basins, the MEDI area presents the worst agreement between REMO and ERS data. This region exhibits the lowest correlation value (0.61) with the highest standard deviation $\left(2.8 \mathrm{~m} \mathrm{~s}^{-1}\right)$ and highest bias $\left(-0.2 \mathrm{~m} \mathrm{~s}^{-1}\right)$. For the other two subbasins, MEDII and MEDIII, the statistical parameters are quite similar to the ones obtained for the whole Mediterranean Basin. 

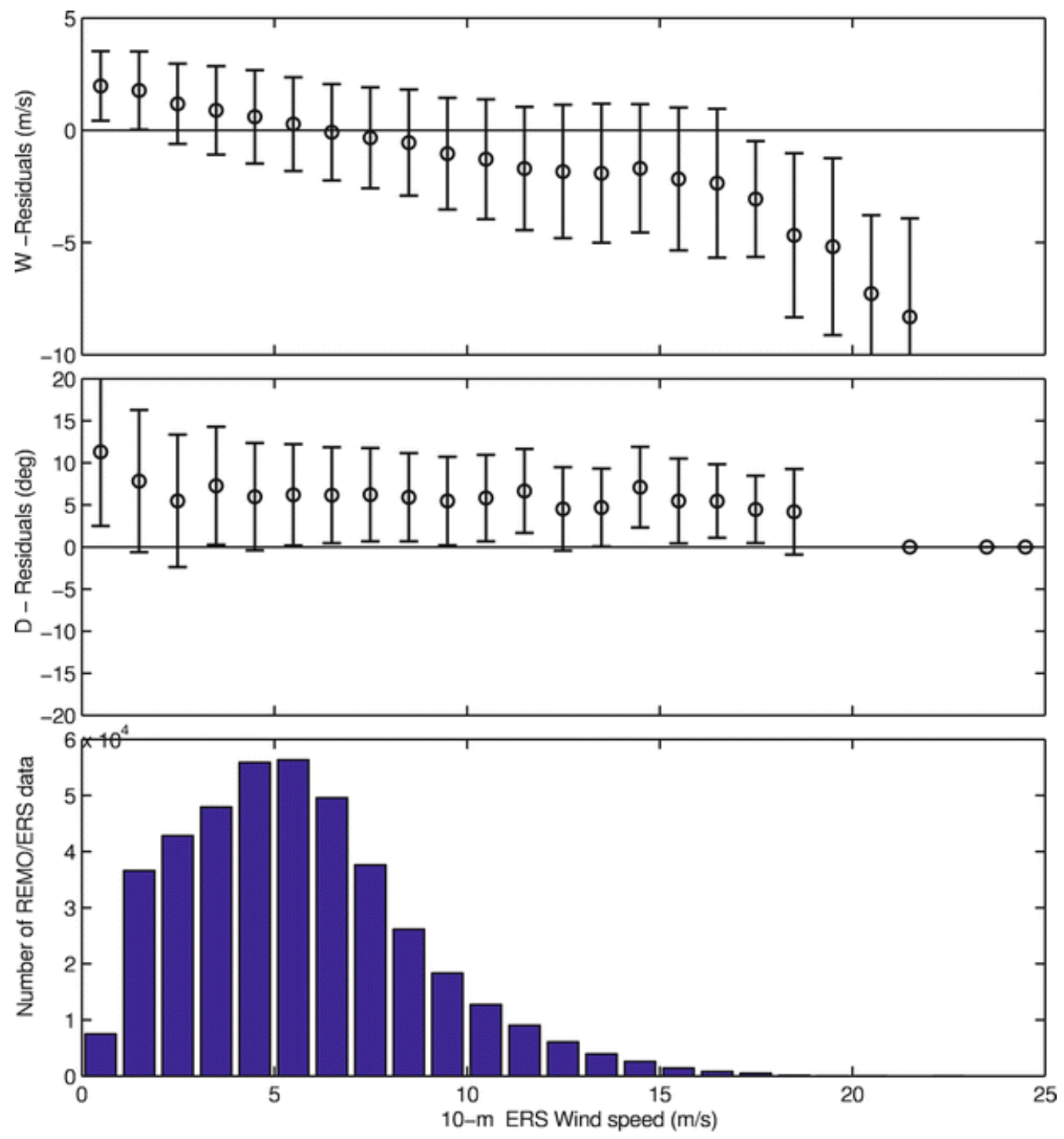

Fig. 5 Mean and standard deviation of the residuals (REMO-ERS) of 10-m wind speed (upper panel) and direction (middle panel) depending on ERS observed 10-m wind speed. Lower panel shows REMO/ERS collocated data frequency histogram, based on ERS 10-m wind speed

Table 2 Statistical comparison of 10-m wind speed and direction between REMO hindcasted data and ERS scatterometer data averaged over the whole Mediterranean Basin (MED) and over three sub-basins: MEDI (6W-5E, 35N-44N), MEDII (6E-15W, 36N-44N) and, MEDIII (15E-30E, $30 \mathrm{~N}-38 \mathrm{~N}$ )

\begin{tabular}{|c|c|c|c|c|c|c|}
\hline \multicolumn{9}{|c|}{} & $10-\mathrm{m}$ wind speed $\left(\mathbf{m ~ s}^{\mathbf{- 1}}\right)$ & \multicolumn{2}{c|}{ Direction (deg) } \\
\hline Basin & $\mathbf{r}$ & Bias & $\boldsymbol{\sigma}_{\mathrm{x}}$ & $\mathbf{a}$ & & $\sigma_{\mathrm{D}}$ \\
\hline MED & .70 & 0.08 & 2.44 & 0.99 & 4 & 29 \\
\hline MEDI & .61 & -0.21 & 2.76 & 1.13 & 0 & 32 \\
\hline MEDII & .73 & -0.02 & 2.45 & 1.05 & 7 & 30 \\
\hline MEDIII & .69 & 0.19 & 2.37 & 0.95 & 4 & 28 \\
\hline
\end{tabular}

$r$ is correlation index, $S$ bias $\left(\mathrm{m} \mathrm{s}^{-1}\right)$, a the wind speed linear regression coefficient and $\sigma_{\mathrm{x}}$ the standard deviation of residuals $\left(\mathrm{m} \mathrm{s}^{-1}\right)$; whereas $D$ and $\sigma_{\mathrm{D}}$ (both in deg) are the mean and the standard deviation of wind direction residuals, respectively 
When looking at the monthly average wind speeds over the whole Mediterranean Basin (figures not shown), overall agreement between REMO and ERS data is found with correlations as high as 0.90 , standard deviation around $0.6 \mathrm{~m} \mathrm{~s}^{-1}$ (with monthly values ranging from $3 \mathrm{~m} \mathrm{~s}^{-1}$ to $10 \mathrm{~m} \mathrm{~s}^{-1}$ ), and bias of the order of $0.1 \mathrm{~m} \mathrm{~s}^{-1}$. Both wind speeds exhibit a strong seasonal signal characterized by a winter wind speed maximum and a summer minimum. Although this signal is observed for every sub-basin, it is in the MEDII zone where this seasonal pattern is the strongest. This may be associated with the important cyclogenetic activity occurring mainly in winter over the Gulf of Genoa.

Results from the above comparisons strengthen the confidence on the REMO surface wind field hindcast over Mediterranean offshore areas.

\section{2. "Indirect" REMO validation}

An "indirect" validation of REMO hindcasted fields (mean sea level pressure and 10-m wind) was performed through comparisons of oceanic model outputs with in-situ oceanographic measurements. For that, the WAM wave model (WAMDI group 1988) was driven with the REMO 10-m wind field over the western Mediterranean Basin.

The simulated wave field was then checked with in-situ measurements through comparisons of various parameters such as significant wave height, mean direction as well as peak and mean period. Likewise, the same 10-m wind field along with the REMO mean sea level pressure were used as forcing data for the HAMSOM sea level model (Fanjul et al. 1997) over the whole Mediterranean Basin. The quality of HAMSOM outputs was verified through comparisons with tide-gauge measurements. Further information about technical details of both oceanic hindcasts is found in Ratsimandresy and Sotillo (2003).

Both oceanic models (WAM and HAMSOM) have been extensively validated in previous studies over the area of interest (Gómez Lahoz and Carretero 1997). Moreover, they are nowadays used as numerical tools for operative oceanic forecast purposes (Carretero et al. 2000). These studies state that the quality of the oceanic model outputs is closely related to the quality of the atmospheric fields used as forcing. This allows us to use the comparisons of oceanic model outputs with in-situ oceanographic measurements as a mean to evaluate indirectly the quality of the atmospheric forcing.

As already mentioned, REMO 10-m wind field was the only forcing field used in the wave integration. This wind forcing plays a determinant role in the simulation of a realistic wave state. Furthermore, in a close basin like the Mediterranean, the smaller contribution of swell makes the regional wind conditions the most important factor in determining the local wave state. This local wave state (observed at a single point) is directly related to the prevailing regional wind conditions existing around the selected point, and not only to the wind measured at this specific location.

Comparisons between the wave state observed at eight offshore buoys, moored along the Mediterranean Spanish coast, and the wave simulated by WAM at the respective closest grid point reveal the existence of a good agreement between observation and simulated data. Significant wave height correlations between 0.68 and 0.84 are obtained. It is worth to note that correlations increase farther from the coast. This spatial quality distribution related to the distance from the coast may be attributed in part to the wind field quality (the wind is also better reproduced in offshore areas in comparison to inland regions, especially when their orography is complex). In addition, non-resolved coastal effects due to an insufficient wave model grid resolution (i.e. bottom friction, shadow and shoaling coastal effects) may also contribute to reduce the quality of simulated waves at some specific shallow water areas (Komen et al. 1994).

An example of temporal evolution of significant wave height obtained with a buoy moored off the north-eastern coast of the Iberian peninsula $\left(49.83^{\circ} \mathrm{N}, 3.19^{\circ} \mathrm{E}\right)$ along with the corresponding waves simulated by WAM is presented in Fig. 6 (upper panel). The simulation agrees well with the observation, being most of the observed peaks reproduced by the WAM forced with REMO winds. 

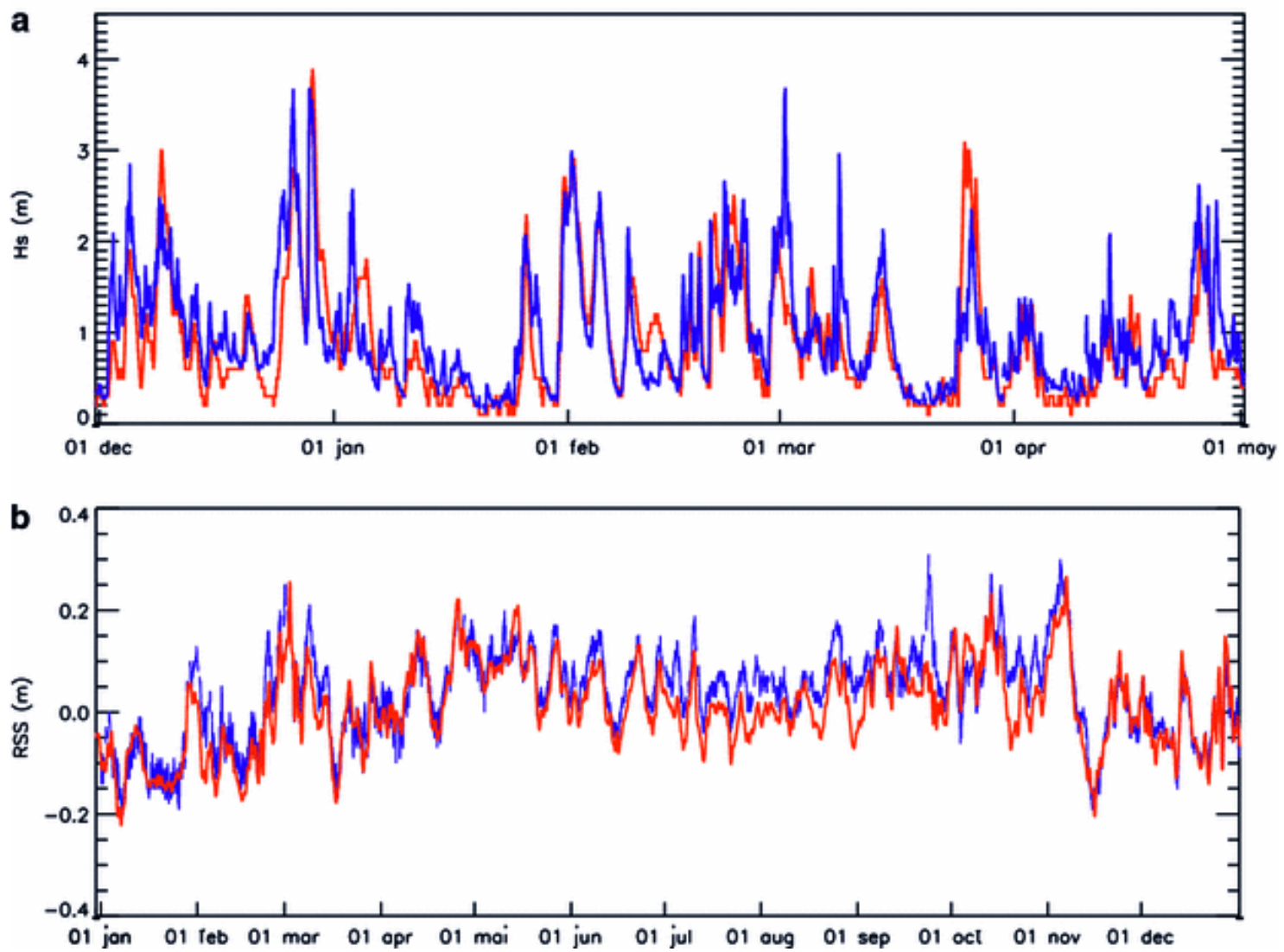

Fig. 6 Temporal evolution of (a) significant wave height (in $\mathrm{m}$ ) at an offshore buoy moored at $(41.83 \mathrm{~N}, 3.19 \mathrm{E})$ and (b) sea level meteorological residual (in $\mathrm{m}$ ) at Barcelona Harbour $(41.35 \mathrm{~N}$, 2.16E). In both cases, observation and simulated data are represented by blue and red lines, respectively

Verification of sea-level height obtained from a HAMSOM run forced with the REMO mean sea level pressure and $10-\mathrm{m}$ wind fields was performed through comparisons with in-situ measurements from nine tide-gauges located at different Atlantic and Mediterranean harbours. Only the meteorological component of the sea level was considered. This component, also called meteorological residual, is obtained after subtracting the astronomical tide from the observed sea level. Despite the fact that this residual contains other non-periodic contribution, it is called meteorological residual due to the determinant role the meteorological conditions have in comparisons to other non-periodic effects. High correlation values (between 0.70 and 0.88 , with six stations over 0.80) are obtained. A 1-year comparison between the observed and simulated meteorological residuals at Barcelona Harbour, Spain $\left(41.35^{\circ} \mathrm{N}, 2.16^{\circ} \mathrm{E}\right)$ is presented as an example in Fig. 6 (lower panel). As in the wave case, the agreement is very good. This ensures somehow the reliability of the atmospheric fields hindcasted by REMO when used as forcing for ocean models. At the same time, it gives some confidence on the quality of REMO data since a realistic ocean simulation can be achieved, only with equally realistic atmospheric fields used to drive such simulation.

The "indirect" atmospheric model validation suggested in the present section is based on the use of oceanographic data as a proxy for prevailing surface pressure and wind conditions. This methodology allows us to have a valuable reference on the reliability of these simulated fields over offshore areas where the lack of meteorological in-situ observations is certainly a shortcoming in the validation process. 


\section{Regional enhancement of global reanalysis}

As above mentioned, the main objective of the atmospheric hindcast performed within the HIPOCAS Project is to create a long-term set of consistent climate data on a regional scale for the Mediterranean domain. After validating the atmospheric hindcast data, we will assess the improvement introduced by the downscaling in relation to already existing climate data sets. Taking into account that the NCEP/NCAR global reanalysis was used to drive the regional REMO run, it seems natural to evaluate the improvement in quality, as well as in accuracy introduced through the dynamical downscaling. Thus, some of the comparisons with observations presented in the previous section were repeated but this time using NCEP global reanalysis data instead of the REMO hindcasted ones. This comparison was carried out separately for the same 15 offshore stations used in Sect. 3.1.1, as well as for other 20 inland stations distributed over the Iberian Peninsula and the Balearic Islands. It was performed with REMO, NCEP, and observation data sets sampled with 6-h frequency. In order to fulfil such comparison it was necessary to interpolate the NCEP reanalysis fields to the REMO grid. In this way, observation from each station will be compared to the REMO and NCEP data extracted from the same grid point (the one closest to the station location). The following surface parameters were considered: mean sea level pressure, 2-m temperature, and 10-m wind field.

Both NCEP and REMO reproduce the mean sea level pressure observed at offshore stations with a similar quality. Figure $7 a$ shows a Quantile-Quantile (Q-Q) plot of mean sea level pressure at CGATA; this plot illustrates how both REMO and NCEP present almost identical quantile distributions that fit very well the observed one. This identical efficiency presented by the reanalysis and downscaled data in reproducing the mean sea level pressure can be linked to the fact that such surface pressure is characterized more by large-scale phenomena rather than by regional features. These large-scale phenomena are already well resolved by the global reanalysis minimizing, therefore, the need of performing a regional downscaling. 

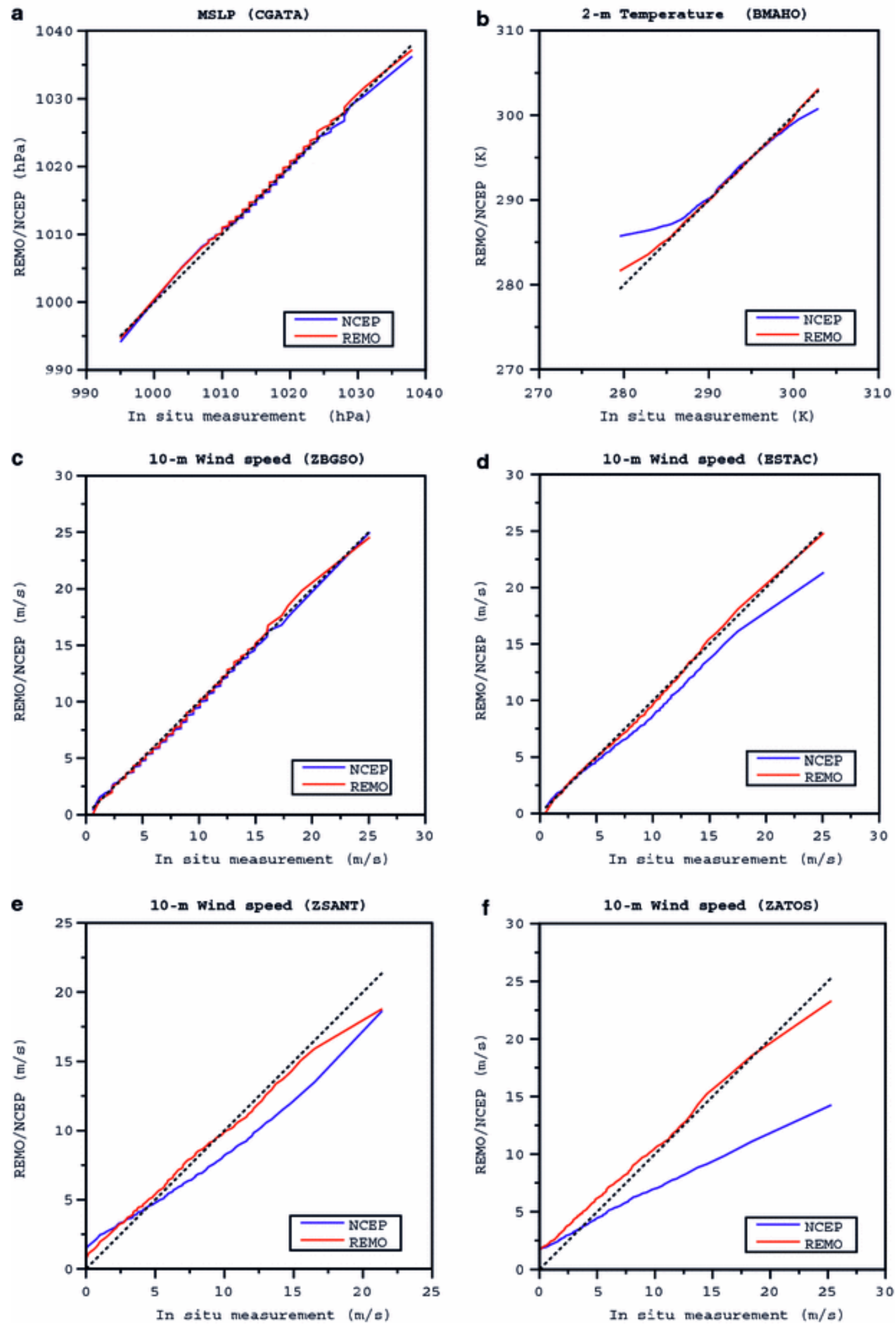

Fig. 7 Quantile-Quantile (Q-Q) plots of REMO hindcasted data (red line) and NCEP global reanalysis (blue line) versus observation: (a) Mean sea level pressure (in hPa) at CGATA offshore station $(36.57 \mathrm{~N}, 2.33 \mathrm{~W})$; (b) 2-m temperature (in K) at BMAHO offshore station $(39.72 \mathrm{~N}$, 4.44E); (c), (d), (e), and (f) $10-\mathrm{m}$ wind speed (in $\mathrm{m} \mathrm{s}^{-1}$ ) at offshore buoys ZBGSO (48.70N, $12.40 \mathrm{~W})$, ESTAC $(36.57 \mathrm{~N}, 2.33 \mathrm{~W})$, ZSANT $(36.26 \mathrm{~N}, 25.50 \mathrm{E})$, and ZATHO $(39.96 \mathrm{~N}, 24.72 \mathrm{E})$, respectively 
On the contrary, the analysis of 2-m temperature reveals differences in the way that REMO and NCEP reproduce the observed 2-m temperature at the offshore stations. These differences are found mainly in extreme values, being not realistically reproduced by the reanalysis. The dynamical downscaling comes to correct this reanalysis shortcoming, and yields more realistic extreme values in both maxima and minima values (Fig. 7b). However, this improvement in the extreme values enhances very slightly global parameters such as correlation, bias, and root men square error.

The improvement introduced by dynamical downscaling with respect to reanalysis data is even better appreciated for 10-m wind field. Table 1 illustrates that REMO shows higher correlation values and lower root mean square errors in comparison to NCEP. According to this result, one can conclude that the hindcast data reproduce better and more accurately offshore surface winds than NCEP reanalysis. Ten-meter wind Q-Q plots for four different stations are represented in Fig. 7c-f. They are four selected cases to illustrate the improvement introduced by the downscaling. The magnitude of such improvement depends on various geographical factors, mainly the type of basin, the distance to the coast, and the complexity of the orography surrounding the basin. REMO improves the NCEP performance in characterizing the 10-m wind field. This is more significant over the Mediterranean than over the Atlantic as shown by the comparison of Q-Q plot results from the Mediterranean stations (ZATOS and ZSANT) with those from the Atlantic stations (ZBGSO and ESTAC). The effect of the coast can be appreciated by comparing the Q-Q plots from coastal stations (ESTAC in the Atlantic and ZATOS in the Mediterranean) with other offshore buoys moored farther from the coast (ZBGSO and ZSANT, in the Atlantic and the Mediterranean, respectively). The improvement introduced by the hindcast seems to be higher as we move onshore.

By generalizing the results, we could state that in the Atlantic Basin, specially far from coastal areas, the NCEP reanalysis is already an useful data set to characterize realistically the $10-\mathrm{m}$ wind field. Therefore, the application of a downscaling technique will not introduce any substantial improvement (Fig. 7c). As we move towards coastal regions (Fig. 7d) the downscaling becomes more efficient and the differences between reanalysis and downscaled data get more relevant. Figure $7 f$ shows how this enhancement of global reanalysis data by means of dynamical downscaling is a highly effective technique in improving the $10-\mathrm{m}$ wind field characterization over coastal areas of complex orography. Note that this improvement gets more and more noticeable for extreme wind values.

In the Mediterranean, the extreme wind events linked to regional winds (i.e. Bora, Tramontana, mistral, and so on) are better characterized through the downscaled data (Sotillo 2003). Figure 8 shows a Bora event occurring between 11th and 16th February 1994 at ZADRI station (moored in the Northern Adriatic Sea). It can be observed that both NCEP reanalysis and REMO hindcasted data reproduce the wind peak measured during the event. However, NCEP reproduces only a maximum of $12 \mathrm{~m} \mathrm{~s}^{-1}$ (out of $23 \mathrm{~m} \mathrm{~s}^{-1}$ given by the measurement), whereas REMO is able to give a more realistic peak of $17 \mathrm{~m} \mathrm{~s}-1$. This difference in the skill of the NCEP and the REMO data sets in reproducing the strong storm occurrence was further studied in an extensive extreme wind analysis. The first step of such analysis consists on the definition of a criterion to select those peaks considered as extreme events. For that, a threshold wind speed value was specified. The independence between the selected peaks was achieved by ensuring at least $48 \mathrm{~h}$ period between two successive extreme events (Palutikof et al. 1999). Different speed threshold values are obtained individually for each of the 15 offshore stations using the following expression: where P 75 is the 75th percentile speed value and $d$ is the interquartile distance, defined as the difference between the 75th and the 25th percentile values. The choice of this threshold speed as a function of the percentile distribution of the sample, instead of a single percentile value (e.g. 90th percentile) allows to minimize problems associated to the existence of inconsistent measurements (Trenberth and Paolino 1980; Afifi and Clark 1990). 


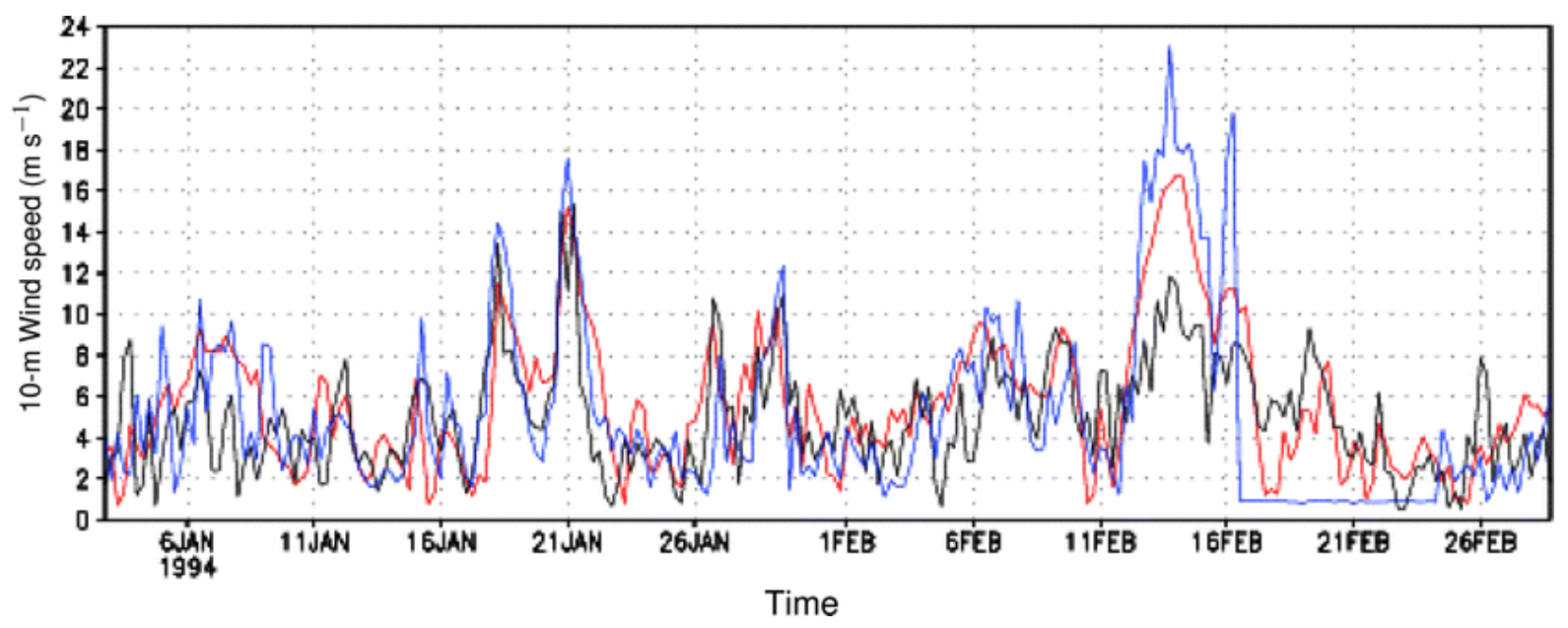

Fig. 8 Temporal evolution of $10-\mathrm{m}$ wind speed $\left(\mathrm{m} \mathrm{s}^{-1}\right)$ at the ZADRI offshore station $(12.50 \mathrm{~N}$, 45.30E) in the Northern Adriatic Sea: REMO hindcasted data (red line), NCEP reanalysis data (black line), and in-situ measurements (blue line)

Figure 9a shows the threshold velocities calculated from the observations at the 15 offshore stations. It can be seen that the extreme wind events in the Atlantic open waters are characterized by wind speeds higher than $13 \mathrm{~m} \mathrm{~s}-1$. It is also worth to note that at coastal stations the threshold values are lower (between $10 \mathrm{~m} \mathrm{~s}^{-1}$ and $12 \mathrm{~m} \mathrm{~s}^{-1}$ in the northwestern coast of the Iberian Peninsula and between $9 \mathrm{~m} \mathrm{~s}-1$ and $10 \mathrm{~m} \mathrm{~s}-1$ around the Strait of Gibraltar). For the Mediterranean offshore stations, the threshold velocities range between $8 \mathrm{~m} \mathrm{~s}^{-1}$ and $13 \mathrm{~m} \mathrm{~s}-1$, with no specific spatial pattern. 

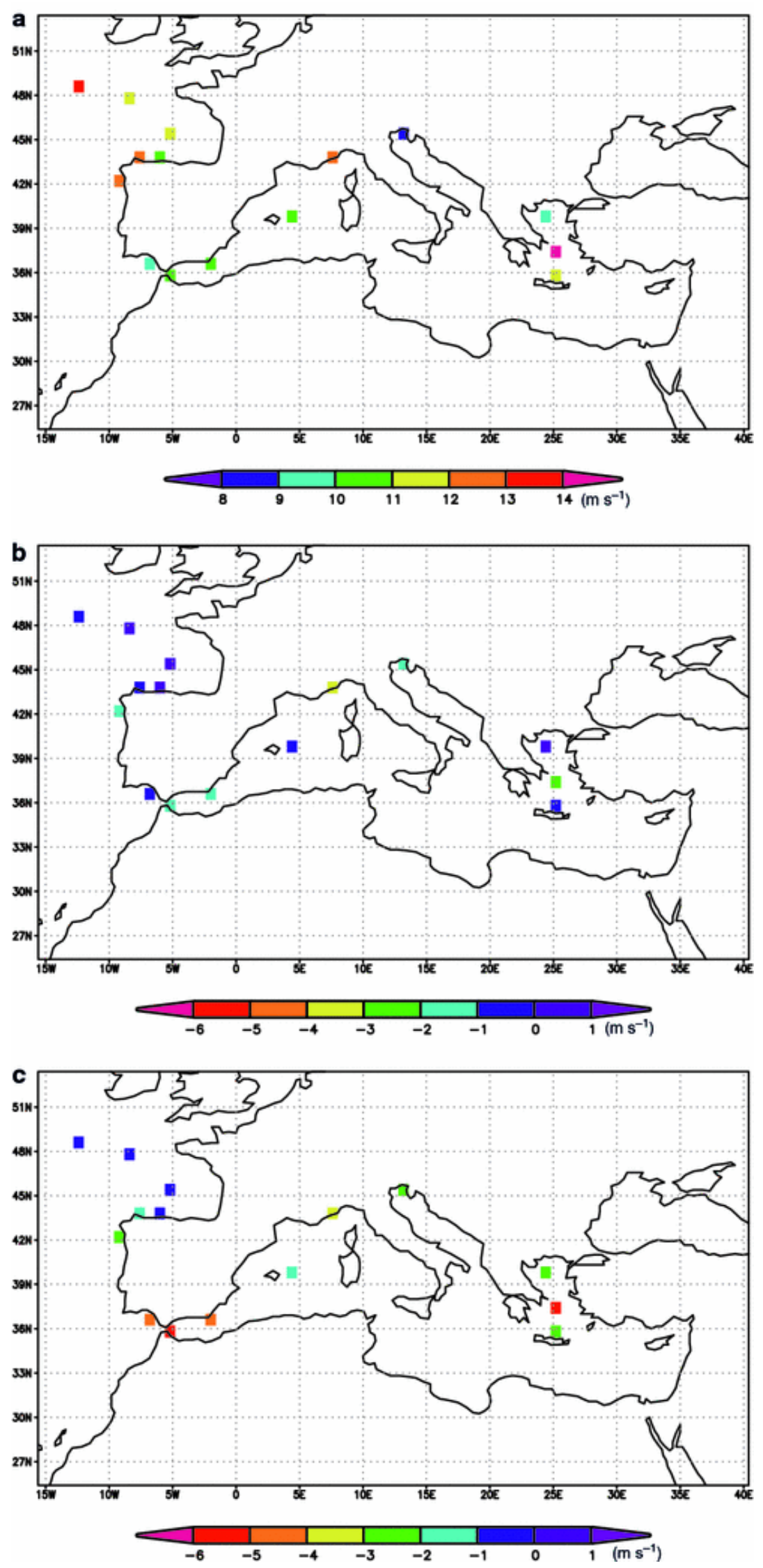

Fig. 9 (a) Extreme wind speed thresholds (in $\mathrm{m} \mathrm{s}^{-1}$ ) obtained from observations at 15 offshore stations, (b) differences (in $\mathrm{m} \mathrm{s}^{-1}$ ) between the REMO extreme wind speed threshold values and 
the ones obtained from the in-situ measurements for each of the 15 offshore buoy station, (c) the same, but differences are calculated this time between NCEP and observations

The differences between the extreme threshold values calculated from REMO data and the observations on one side (Fig. 9b), and the NCEP reanalysis data and the observations on the other side (Fig. 9c) provide valuable information about the different behaviour of hindcasted and reanalyzed data in characterizing extreme wind regimes. It can be noted that NCEP reanalysis data are not able to reproduce realistic extreme wind speeds, especially in the Mediterranean. An important NCEP underestimation of the observed extreme wind speed threshold values is obtained, being as high as $5 \mathrm{~m} \mathrm{~s}^{-1}$ at some Mediterranean stations. On the other hand, it can be appreciated how REMO corrects this NCEP deficiency, reducing considerably the underestimation. It can be also observed that, in general, wind speed thresholds obtained from the REMO fit the observed ones better than the NCEP reanalysis, showing the former underestimation lower than $4 \mathrm{~m} \mathrm{~s}^{-1}$. Remarkable improvements are introduced by the dynamical downscaling in some Mediterranean stations such as the ones located around the strait of Gibraltar and those located in the Aegean Sea. For these stations, REMO introduces an increase of extreme threshold velocities of up to $4 \mathrm{~m} \mathrm{~s}^{-1}$, with respect to the NCEP ones. The hindcasted values are then closer to the observed ones and thus making them more realistic.

After checking that the differences between model and reanalysis extreme wind speeds represent a real improvement in the characterization of extreme wind regimes at the available offshore stations, a comprehensive comparison between REMO and NCEP were performed over the whole offshore grid points. The objective is to characterize the spatial distribution of such improvement. For that, data from a 5-year period (1997-2001) were used to study the offshore extreme wind speed thresholds characterized by REMO and by NCEP. The choice of this time period was motivated by the fact that it includes most of the above observations used to validate the REMO and NCEP winds. Figure 10c shows differences between REMO and NCEP for this 5year period and for the whole offshore domain. The maximum efficiency of the hindcast (interpreting the REMO-NCEP differences as an improvement on the latter) is found on both sides of the Gibraltar Strait, as well as in the Aegean Sea (with REMO wind speed increases of up to 6 and $5 \mathrm{~m} \mathrm{~s}-1$, respectively). Other Mediterranean offshore areas, that show important differences, are the northern Adriatic Sea, as well as the gulfs of Lyon and Genoa. Figure 10a and $b$ show the geographical distribution of the extreme wind velocities obtained from REMO and NCEP, respectively. 

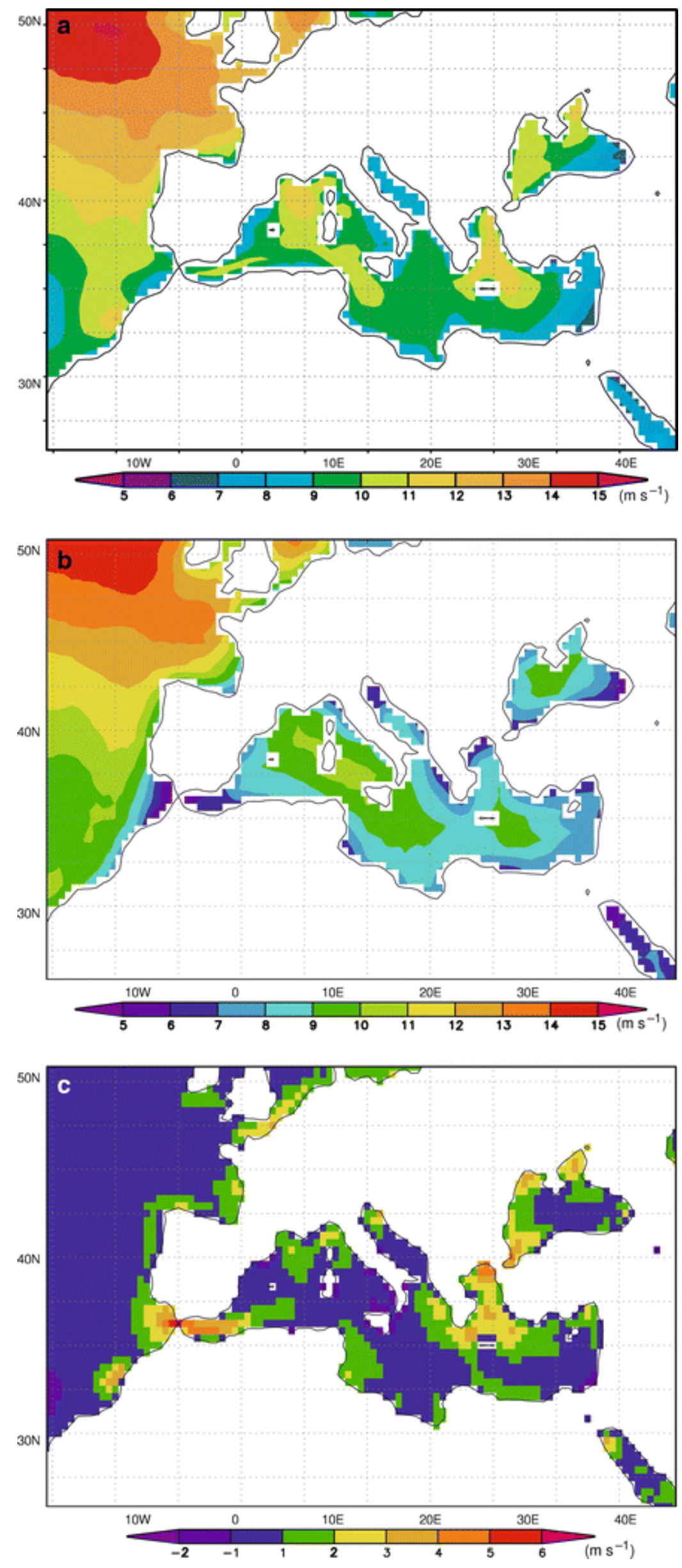
Fig. 10 (a) REMO extreme wind speed thresholds (in $\mathrm{m} \mathrm{s}^{-1}$ ) obtained at every offshore grid point, (b) the same but for NCEP reanalysis data, (c) differences (in $\mathrm{m} \mathrm{s}^{-1}$ ) between the REMO extreme speed threshold values and the ones obtained from NCEP. Calculations were performed over the 1997-2001 time period

It can be appreciated in Fig. 10a that the spatial distribution of REMO extreme winds over the Mediterranean is marked by the existence of high wind areas (namely Gulf of Lyon, Gulf of Genoa, Sicily Channel, and Alboran Sea in the western basin, and the Aegean sea in the eastern Mediterranean Basin). These high wind nuclei, with values comprised between $10 \mathrm{~m} \mathrm{~s}-1$ and $12 \mathrm{~m} \mathrm{~s}-1$, are localized over areas affected by strong regional and local orographic wind enhancements, as well as over areas affected by the Mediterranean typical regional winds (e.g. Mistral, Levante, Aegean-Bora, Etesian). Further information about these leading Mediterranean winds can be found in Brody and Nestor (1980). On the other hand, Fig. 10b shows that these regional structures, which determine the spatial distribution of wind field over the Mediterranean Basin, are not resolved by the NCEP reanalysis. These data exhibit an extreme 10-m wind field marked by the existence of a single high wind area extended along the Mediterranean Basin. The intensity of this nucleus is maximal (never higher than $11 \mathrm{~m} \mathrm{~s}^{-1}$ ) in the middle of the Basin and decreases towards coastal areas. The coarse spatial resolution used in the generation of the global reanalysis represents a significant shortcoming to reproduce the main Mediterranean regional orographic features (Fig. 1 b). The lack of islands such as Corsica, Sardinia, Sicily, and Crete, together with the minimization of the Italian Peninsula in the NCEP orography lead to the presence of the above-referred single high wind area without any orographic modulation along the Mediterranean Basin. Likewise, the NCEP unrealistic characterization of the Strait of Gibraltar and its surroundings plays a determinant role in the already proven ineffective reproduction of the extreme wind conditions over this specific area. This also happens over other Mediterranean sub basins such as the Aegean and Black Sea. This shortcoming is then corrected by the dynamical downscaling.

A complementary study on 10-m wind direction has been performed with the same 15 offshore stations. This directional study has proven that the improvement is not only in the wind speed values but also in the directional distribution of winds. The study consisted on comparing the wind roses obtained from REMO, NCEP as well as the observations. Figure 11 shows the directional distributions for two buoys: CADIZ and BMETE. The first buoy is moored in the Gulf of Cadiz, close of the Strait of Gibraltar in the Atlantic side. The second one is moored in the Gulf of Genoa in the Mediterranean. 
a

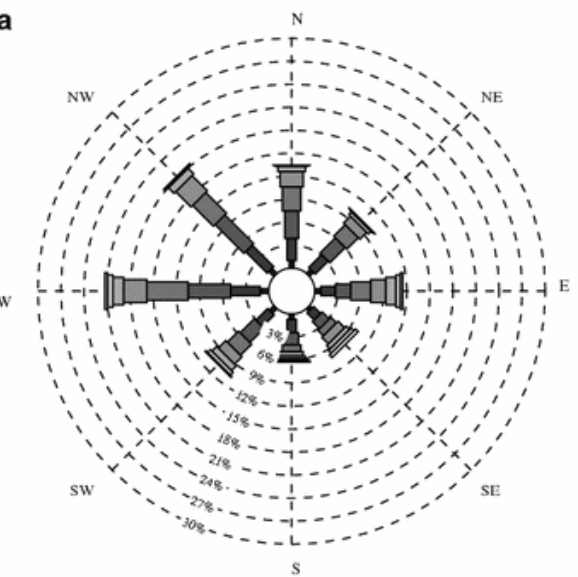

b

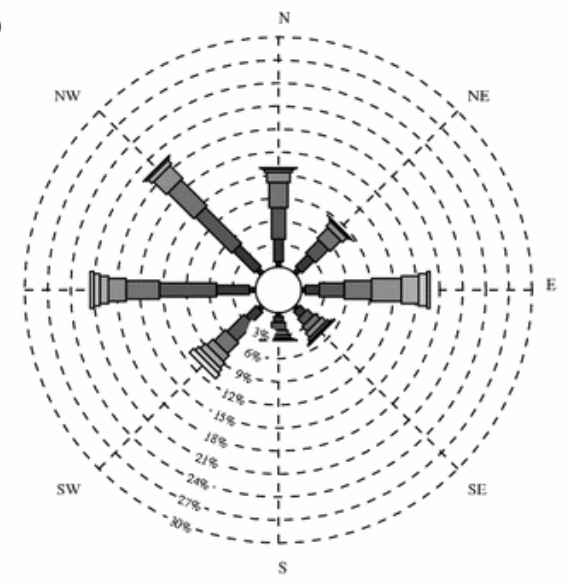

c

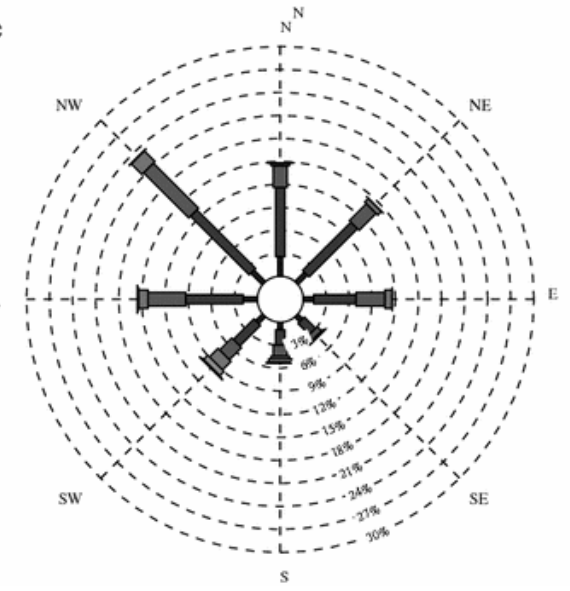

d

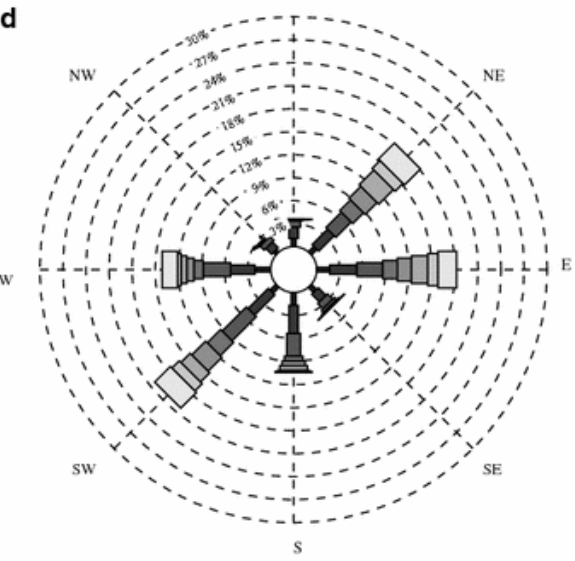

e

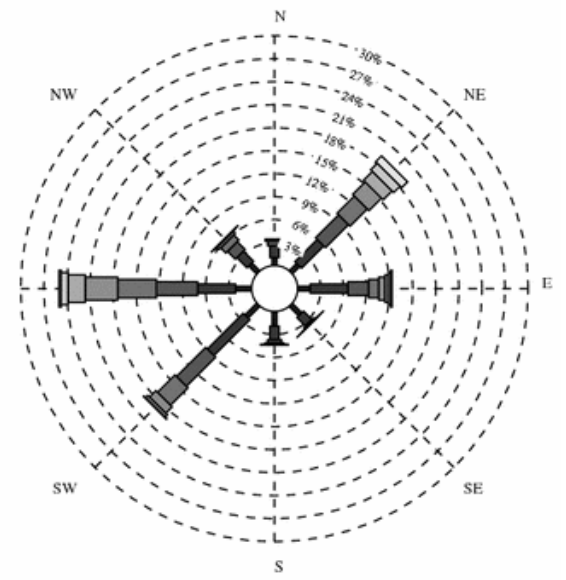

f

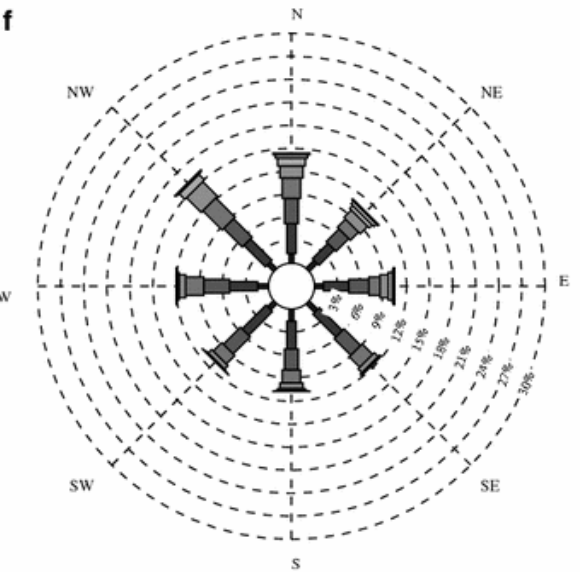

Fig. 11 Ten-metre wind directional distribution at offshore station CADIZ (36.48N, 6.96W). (a) insitu observations, (b) REMO data, and (c) NCEP reanalysis. Same distributions at BMETE station (43.40N, 7.80E) being (d) in-situ measurement, (e) REMO, and (f) NCEP data. Note that these plots show both percentage of occurred frequency and wind speed for eight different sectors (i.e. N, NE, E, SE, S, SW, W, and NW). Grey scale represents wind speed intervals of $3 \mathrm{~m} \mathrm{~s}^{-1}$

A visual inspection of the results obtained with CADIZ shows that NCEP reanalysis is unable to reproduce realistically the observed wind direction. In addition, wind speed is clearly underestimated. On the contrary, and despite of a slight trend to favour easterlies, REMO wind direction distribution tends to be more similar to the observed one. This similarity is also more appreciated in terms of wind speeds. In this specific area, coarse resolution determines negatively the NCEP global reanalysis performance. This global reanalysis limitation is solved by the ability of REMO to better characterize the regional topographic features (e.g. the Strait of Gibraltar). 
The Gulf of Genoa, where BMETE buoy is moored, is a very important orographically induced cyclogenetic area in the Mediterranean. For this reason, wind data measured at this station are an useful tool to evaluate model performance in wind simulation. The observed wind regime (Fig. 11d) is marked by a dual structure with prevailing winds from SW-W and from E-NE. The formers are related to systems coming from the Atlantic and are uniformly distributed along the whole year. The E-NE winds, on the other hand, are more linked to the existence of low-pressure systems centred in the Gulf of Genoa. They take place mainly in winter and spring seasons (seasonal wind roses not shown). This observed directional wind distribution is simulated in a similar way by the REMO data (Fig. 11e). On the contrary, NCEP is unable to reproduce the observed wind duality. It exhibits rather an almost circular distribution (Fig. 11f).

One of the possible explanations of this lack of favoured directions could be the unrealistic characterization of the Alps ranges by NCEP global reanalysis. While the observations and REMO show an almost complete suppression of N-NW winds, NCEP presents an anomalous maximum in wind occurrence for these flows. This could be explained by the lower barrier action performed by unrealistic Alps with insufficient height and friction capacity. This unrealistic Alps could also be the reason of the NCEP decrease in both frequency and intensity of the E-NE winds that are related to the cyclogenesis occurring at the lee of such a range.

The results presented in this section enhance the confidence in the REMO hindcast data. At the same time, they highlight the efficiency of the regional enhancement performed on the NCEP global reanalysis through dynamical downscaling.

\section{Conclusions}

A 44-year (1958-2001) high resolution hourly atmospheric hindcast was performed, by EPPE within the EU-funded HIPOCAS Project, over the Mediterranean Basin. The hindcasted data was produced by means of dynamical downscaling from the NCEP/NCAR global reanalysis using the regional atmospheric model REMO. A spectral nudging technique was applied on the simulated wind field, keeping it close to the imposed time-variable large-scale atmospheric state provided by the NCEP forcing. The use of global reanalysis data, instead other data sources, to drive the regional model was motivated by the need of a guaranteed temporal homogeneous output over the whole multi-decade run period.

Advances in regional climate modelling must be strongly based on analysis of simulated physical processes in comparisons with observations. Validation of simulated surface atmospheric fields has been an issue of maximum concern. To do this, an exhaustive REMO validation has been performed in order to enhance the confidence of the hindcasted data as well as to detect their limitations.

A "direct" validation of REMO output has been carried out by comparing them with observations. These comprise observation data from various sources such as in-situ offshore and in-land meteorological surface measurements and winds derived from ERS scatterometer. Comparisons between hindcasted and observation data from offshore buoys, located in both the Atlantic and the Mediterranean, reveal a very good model performance in terms of mean sea level pressure and 2-m air temperature. The offshore $10-\mathrm{m}$ wind is also well simulated by REMO. However, the hindcast quality shows a spatial pattern characterized by a higher REMO simulation skill over the Atlantic than over the Mediterranean. Differences between both basins are mainly related to the orography complexity found around the Mediterranean Basin. Comparisons between hindcasted data and 10-m wind derived from ERS-1/2 scatterometer data over the whole Mediterranean Basin for the decade of 1991-2001 has also demonstrated REMO capability. All this strengthens the confidence of REMO model to simulate the atmospheric state over the Mediterranean.

Additionally, an "indirect" verification of REMO hindcasted mean sea level pressure and 10-m wind field has been carried out through comparisons of REMO-forced ocean model outputs and in-situ oceanographic measurements. Such "indirect" validation gives a measure of the quality of the REMO hindcasted data over offshore areas where meteorological observations are scarce. Analogous comparisons carried out between offshore and in-land observations and NCEP global reanalysis, on one side, and REMO on the other, showed that dynamical downscaling introduces a substantial improvement in characterizing the 2-m temperature and $10-\mathrm{m}$ wind fields. In the case of 2-m temperature the improvement is more important inland than over offshore areas, 
specially for the extreme values. Such improvement is due to the better simulation of regional features (land-sea distribution, orography, presence of islands,...) resolved by the dynamical downscaling.

The dynamical downscaling performed through REMO introduces substantial regional enhancement of the global reanalysis in the 10-m wind field. This is more important in the Mediterranean than in the Atlantic, and especially over areas with complex orography. In these Mediterranean areas, the NCEP global reanalysis are not an adequate tool to assess extreme wind events. Dynamical downscaling performed corrects this limitation leading to more realistic wind speeds. The 10-m wind field improvement is not only in terms of wind speed but also in terms of directional distribution of winds.

To date, this 44-year HIPOCAS hourly atmospheric database is the only one with high spatial and temporal resolution for the whole Mediterranean Basin. This database introduces an important regional enhancement over global reanalysis data. These characteristics make the database a quite useful tool for regional climatic studies over the Mediterranean domain.

Acknowledgements The present work was realized within the EU-funded HIPOCAS Project $\left(\mathrm{N}^{\circ}\right.$ EVK2-1999-00248). Ente Público Puertos del Estado (EPPE) has been responsible for the implementation and execution of atmospheric and oceanographic (waves and sea level) hindcast systems for the whole Mediterranean Basin. In addition, EPPE now maintains a database that includes the atmospheric and oceanographic parameters generated by these hindcasts. The authors wish to thank to all the institutions and people who provided us with data: NCEP Reanalysis data were provided by the NOAA-CIRES Climate Diagnostics Center, Boulder, Colorado, USA from their Website at http://www.cdc.noaa.gov, INM (Spain), IFREMER (France), MeteoFrance (France), NCMR (Greece), Dr. Luigi Cavalieri (ISDGM, Italy). Thanks should also be addressed to an anonymous journal reviewer, as well as to Dr. H. Von Storch, Dr. R. Weisse, and F. Fesser (GKSS) for their constructive comments. Dr. D. Jacobs and R. Podzun (MPI) for their valuable help with REMO model and O. Serrano (EPPE) for his useful help with data analysis.

\section{References}

Afifi A, Clark W (1990) Computer aided multivariated analysis, 2nd ed. Van Nostrand Reinhold, New York, pp 505

Bentamy A, Grima N, Quilfen A (1998) Validation of the gridded weekly and monthly wind fields calculated from ERS-1 scatterometer wind observations. Global Atmos and Ocean Syst 6:373396

Bentamy A, Quilfen Y, Flament P (2002) Scatterometer wind fields: a new release over the decade 1991-2001. Can J Remote Sensing 28:431-444

Bentamy A, Katsaros KB, Alberto M, Drennan WM, Forde EB, Roquet H (2003) Satellite estimates of wind speed and latent heat flux over the global oceans. J Clim 16:637-656

Brody LR, Nestor MJR (1980) Regional forecasting aids for the Mediterranean Basin (Handbook for forecasters in the Mediterranean, Part 2). Naval Environmental Prediction Research Facility, Monterey, California, pp 178

Carretero JC, Álvarez Fanjul E, Gómez Lahoz M, Pérez B, Rodríguez I (2000) Ocean forecasting in narrow shelf seas: application to the Spanish coasts. Coastal Eng 41:269-293

Cox AT, Swail VR (2001) A global wave hindcast over the period 1958-1997: validation and climate assessment. J Geophys Res 106:2313-2329 
Davies HS (1976) A lateral boundary formulation for multi-level prediction models. Q J R Meteorol Soc 102:405-418

DKRZ-Modelling group (1994) The ECHAM3 atmospheric general circulation model. Technical Report 6, Deutsches KlimaRechenZentrum, Hamburg, pp 184

Ebisuzaki W, Kanamitsu M, Potter J, Fiorino M (1998) An overview of Reanalysis-2. Proceedings of climate diagnostic workshop. Miami, Florida

Fanjul EA, Rodríguez I, Pérez B (1997) A description of the tides in the eastern north Atlantic. Progr Oceanogr 40:217-244

Feser F, Weisse R, Von Storch H (2001) Multi-decadal atmospheric modelling for Europe yields multi-purpose data. Eos Transactions 82(28):305-310

Frank HP (2001) Extreme winds over Denmark from the NCEP/NCAR Reanalysis. Technical Report Riso-R-1238 (EN). Riso National laboratory, Roskilde, pp 28

Gibson JK, Kallberg P, Uppala S, Hernandez A, Ñomura A, Serrano E (1997) ERA description. ECMWF Re-analysis Project Report Series 1, Reading, pp 72

Giorgi $F$ (1990) On the simulation of regional climate using a limited area model nested in a general circulation model. J Clim Res 3:941-963

Gómez Lahoz M, Carretero JC (1997) A two-way nesting procedure for the WAM model: application to the Spanish coast. Transaction of the ASME 19:20-24

Graber HC, Ebutchi N, Vakkayl R (1996) Evaluation of ERS-1 scatterometer winds with wind and waves ocean buoy observations. Technical report RSMAS 96-003. University of Miami, Miami, Florida

Guedes C, Carretero JC, Weisse R, Alvarez E (2002) A 40 years hindcast of wind, sea-level and waves in European waters. Proceedings of OMAE 2002: 21st international conference on offshore mechanics and arctic engineering. Oslo, Norway

Günther H, Rosenthal W, Stawarz M, Carretero JC, Gomez M, Lozano I, Serrano O, Reistad M (1998) The wave climate of the northeast atlantic over the period 1955-1994: the WASA wave hindcast. The Global Atmos and Ocean Syst 6:121-163

Jacob D, Podzun R (1997) Sensitivity studies with the regional climate model REMO. Meteor Atmos Phys 63:119-129

Jones PD (1995) The instrumental data record, its accuracy and use in the attempts to identify the " $\mathrm{CO}_{2}$ signal". In: Von Storch, Navarra (eds) Analysis of climate variability, applications of statistical technics. Springer, pp 53-76

Juang HH, Hong HS, Kanamitsu M (1997) The NCEP regional spectral model: an update. Bull Am Meteorol Soc 78:2125-2143

Kalnay E, Kanamitzu M, Kistler R, Collins D, Deaven D, Gandin L, Iredell M, Saha S, White G, Woolen J, Zhu Y, Chelliah M, Ebisuzaki W, Higgins W, Janowiak J, Mo KC, Kopelewski C, Wang J, Leetmaa A, Reynolds R, Jeene R, Joseph D (1996) The NCEP/NCAR 40-year reanalysis 
project. Bull Am Meteorol Soc 77:437-471

Karl TR, Quayle RG, Groisman PY (1993) Detecting climate variations and change, new challenges for observing and data management systems. J Clim 6:1481-1494

Kidson JW, Thompson CS (1998) Comparisons of statistical and model-based downscaling techniques for estimating local climate variations. J Clim 11:735-753

Komen GJ, Cavaleri L, Donelan M, Hasselmann K, Hasselmann S, Janssen PAEM (1994) Dynamics and modelling of ocean waves. Cambridge University Press, Cambridge, pp 560

Louis JF (1979) A parametric model of vertical eddy fluxes in the atmosphere. Boundary layer meteorol 17:187-202

Majewski D (1991) The Europa-Modell of the Deutscher Wetterdienst. ECMWF seminar on numerical methods in atmospheric models 2:147-191

Mesinger $\mathrm{F}$ et al. (2003) NCEP regional reanalysis symposium on observing and understanding the variability of water in weather and climate. AMS Annual meeting. Long Beach, California

Morcrette J, Smith L, Fouquart Y (1986) Pressure and temperature dependence of the absorption in long wave radiation parameterizations. Beitr Phys Atmosph 59:455-469

Nordeng TE (1994) Extended versions of the convective parameterization scheme at ECMWF and their impact on the mean and transient activity of the model in the tropics. Technical Report 206, ECMWF Res. Department, Reading, pp 25

Palitikof JP, Brabson BB, Lister DH, Adcock ST (1999) A review of methods to calculate extreme wind speeds. Meteorological applications 6:119-132

Parker DE, Folland CK, Ward MN, Maskell K, Bevan A, Jackson M (1993) Ocean-atmosphere climatic fluctuations on interannual to century time scales. Publ. of the Hadley Centre for Climatic Prediction and Research UKMO, Brackneel, Berks

Podzun R, Cress A, Majewski D, Renner V (1995) Simulation of European climate with a limited area model. Part II: AGCM boundary conditions. Beitr Phys Atmos 68:205-225

Quilfen Y, Bentamy A, Katsaros K, Lorand G (1999) Estimation of ocean-atmosphere turbulent fluxes from satellite measurements. In OCEANOBS99 - Proceedings of international conference on the ocean observing system for climate, St Raphael, pp 18-22

Ratsimandresy AW, Sotillo MG (2003) Reanalisis de 44 años (1958-2001) del clima oceánico y atmosférico en el Mar Mediterráneo: Informe técnico de la contribución de Puertos del Estado al proyecto europeo HIPOCAS. Technical Report. Ente Público Puertos del Estado, Madrid, pp 397

Reynolds RW, Smith TM (1994) Improved global sea surface temperature analysis using optimum interpolation. J Clim 7:929-948

Rinke A, Dethloff K (2000) The influence of initial and boundary conditions on the climate of the Arctic in a regional climate model. Clim Res 14:101-113

Roeckner E, Arpe K, Bengtstsson L, Christoph M, Claussen M, Dumenil L, Esch M, Giorgetta M, 
Schlese U, Schulzweide U (1996) The atmospheric general circulation model ECHAM4: model description and simulation of present day climate. Technical Report 218. Max Planck Institute für Meteorologie, Hamburg, pp 102

Rood RB, Hou AY, Pawson S, Schubert SD (2001) Reanalysis efforts in the United States: NASA and National Reanalysis Program. ECMWF Workshop on reanalysis. Reading

Simmons AJ, Burridge DM (1981) An energy and angular momentum conserving vertical finitedifference scheme and hybrid vertical coordinates. Mon Weather Rev 109:158-166

Sotillo GS (2003) High-resolution multi-decadal atmospheric reanalysis in the Mediterranean Basin. PhD dissertation. Universidad Complutense de Madrid, Madrid, pp 209

Sundquist H (1978) A parameterization scheme for non-convective condensation including prediction of cloud water content. Q J R Meteorol Soc 117:1641-1657

Tiedtke M (1989) A comprehensive mass flux scheme for cumulus parameterization in large scale models. Mon Weather Rev 117:1779-1800

Trenberth KE, Paolino DA (1980) The northern hemisphere sea level pressure data set: trends, errors and discontinuities. Mon Weather Rev 108:856-872

Uppala S (2001) ECMWF Reanalysis 1957-2001, ERA-40. ECMWF Workshop on reanalysis. Reading, UK

Von Storch H (1999) The global and regional climate system. In: Von Storch H, Flöser G (eds) Springer-Verlag, pp 3-36

Von Storch H, Zwiers FW (1999) Statistical analysis in climate research. Cambridge University Press, Cambridge, pp 484

Von Storch H, Langenberg H, Feser F (2000) A spectral nudging technique for dynamical downscaling purposes. Mon Weather Rev 128:3664-3673

WAMDI Group (1988) The WAM model - a third generation ocean wave prediction model. J Phys Oceanogr 18:1775-1810 